PURQUERIO, L. F. V.; CECÍLIO FILHO, A.B. Concentração de nitrogênio na solução nutritiva e número de frutos sobre a qualidade de frutos de melão. Horticultura Brasileira, Brasília, v.23, n.3, p.831-836, jul-set 2005.

\title{
Concentração de nitrogênio na solução nutritiva e número de frutos sobre a qualidade de frutos de melão
}

\author{
Luis Felipe Villani Purquerio'; Arthur Bernardes Cecílio Filho² \\ ${ }^{1}$ Instituto Agronômico de Campinas, Av. Barão de Itapura, 1481, C. Postal 28, 13001-970 Campinas-SP; E-mail: \\ purquerio@fca.unesp.br; ${ }^{2}$ UNESP-FCAV, Depto. Produção Vegetal, Via de acesso Prof. Paulo Donato Castellane, s/n, $14884-900$ \\ Jaboticabal-SP; Bolsista do CNPq; E-mail: rutra@fcav.unesp.br; felipe@iac.sp.gov.br
}

\section{RESUMO}

O trabalho foi conduzido em ambiente protegido, na UNESPFCAV, em Jaboticabal (SP), de junho a novembro de 2001, com o objetivo de avaliar a qualidade dos frutos do meloeiro (Cucumis melo var. reticulatus), híbrido Bônus $\mathrm{n}^{\circ} 2$, cultivado em sistema hidropônico NFT, em função da concentração de nitrogênio na solução nutritiva $\left(80 ; 140 ; 200\right.$ e $\left.300 \mathrm{mg} \mathrm{L}^{-1}\right)$ e do número de fruto por planta (2; 3; 4 e livre). O delineamento experimental foi de blocos ao acaso, em parcelas subdivididas, com seis repetições. O teor de sólidos solúveis totais e acidez total titulável foram maiores em frutos colhidos de plantas com menor número de frutos pré-estabelecidos. O aumento da concentração de $\mathrm{N}$ na solução nutritiva proporcionou aumento na acidez total titulável e nenhum efeito sobre o teor de sólidos solúveis totais. Houve redução nos diâmetros longitudinal, transversal e na espessura do mesocarpo com o aumento da concentração de $\mathrm{N}$, bem como com o aumento do número de frutos por planta. $\mathrm{O}$ índice de formato de fruto manteve-se igual ou muito próximo a 1.

Palavras-chave: Cucumis melo var. reticulatus, nutrição de plantas, cultivo sem solo, hidroponia, qualidade.
ABSTRACT

Nitrogen concentration in nutrient solution and number of fruits on quality of melon fruits

The effect of nitrogen concentrations (80; 140; 200 and $300 \mathrm{mg}$ $\left.\mathrm{L}^{-1}\right)$ and fruit number per plant $(2 ; 3 ; 4$ and free setting), on the quality of net melon fruits (Cucumis melo var. reticulatus, Bonus $\mathrm{n}^{\circ} 2$ hybrid) was investigated. The experiment was carried out at UNESP-FCAV, Jaboticabal, Brazil, using a NFT hydroponic system, from June to November/2001. The experimental design was of randomized split plots, with six replications. Total soluble solids content and total acidity were higher in fruits harvested from plants with a smaller number of pre-set fruits. A slight increase was observed on total acidity due to the increase of nitrogen concentration in nutrient solution, without any significant effect on total soluble solids. An increase of the $\mathrm{N}$ concentration and the number of fruits per plant resulted in a reduction of fruit longitudinal and transversal diameters and pulp thickness. Fruit shape index was equal or close to one.

Keywords: Cucumis melo var. reticulatus, plant nutrition, soilless cultivation, hydroponics, quality.

(Recebido para publicação em 17 de julho de 2004 e aceito em 12 de junho de 2005)

$\mathrm{O}$ nitrogênio está relacionado com a fotossíntese, respiração, desenvolvimento e atividade das raízes, absorção iônica de outros nutrientes, crescimento e diferenciação celular (EPSTEIN, 1975; MENGEL; KIRKBY, 1987; MARSCHNER, 1995). Também, apresenta importante função como constituinte de aminoácidos e proteínas, aminas, amidas, amino-açúcares, purinas e pirimidinas, alcalóides, coenzimas, vitaminas e pigmentos (MALAVOLTA et al., 1997). Assim, o nitrogênio é um dos nutrientes que promove maiores modificações morfo-fisiológicas na planta, com possibilidade de alterar o número, o peso e a qualidade dos frutos (MARSCHNER, 1995).

No meloeiro, a deficiência de nitrogênio diminui o número de flores hermafroditas, determina alterações no formato e na coloração do fruto, redução do número e peso do fruto, além de limitar do crescimento vegetativo como um todo (PRABHAKAR et al., 1985; FARIA et al., 1994; 2000). Compromete a qualidade do fruto, seja ocasionando polpa mole (BHELLE; WILCOX, 1986), seja apresentando menor teor de sólidos solúveis (FARIA et al., 1994). Por outro lado, sabe-se que o excesso de nitrogênio promove crescimento vegetativo excessivo em detrimento do reprodutivo (MENGEL; KIRKBY, 1987; MARSCHNER, 1995). Purquerio et al. (2003), em cultivo de melão rendilhado em hidroponia, verificaram que aumentos na concentração de nitrogênio da solução nutritiva (80 a 300 mg $\mathrm{L}^{-1}$ de $\mathrm{N}$ ) promoveram maiores percentuais de peso seco da parte aérea (folhas e hastes) em relação ao peso seco total acumulado pela planta, com reflexo negativo sobre o acúmulo de peso seco pelo fruto. Observou-se redução na produtividade comercial com o incremento de $\mathrm{N}$ na solução nutritiva, sendo ainda observada redução do peso mé- dio do fruto com elevação da disponibilidade do nutriente. As alterações manifestadas sobre a fisiologia da planta, e expressas principalmente no crescimento vegetativo, podem afetar a qualidade dos frutos. Purquerio et al. (2003) observaram que o incremento na concentração de N na solução nutritiva promoveu aumento na acidez total titulável dos frutos, possivelmente resultado de um atraso da maturação dos frutos, decorrente do maior teor de $\mathrm{N}$ presente na solução nutritiva.

Outro fator que pode influenciar a qualidade dos frutos de meloeiro é o número de frutos por planta, uma vez que altera a relação área foliar por fruto, ou seja, modifica a relação fonte e dreno. Monteiro e Mexia (1988), verificaram que, quanto maior for a área foliar por fruto de melão, tanto maiores serão o peso e o teor de sólidos solúveis. Também verificaram maior teor de sólidos solúveis em frutos provenientes 
de plantas conduzidas com um só fruto. Ishikawa et al. (1976) citados por Monteiro e Mexia (1988) verificaram que a redução do número de folhas por planta afetou o número de frutos e a produção, existindo uma correlação positiva entre a produção e a área foliar da planta.

Modificações em peso médio, teores de sólidos solúveis e de açúcares de frutos de melão foram observados por Nelson (1992), Pardossi et al. (1994), Faria et al. (1994) e Faria et al. (2000), quando alteraram a quantidade de nitrogênio fornecida à planta.

O objetivo deste trabalho foi avaliar a influência da concentração de nitrogênio na solução nutritiva e do número de frutos por planta sobre a qualidade de frutos do melão rendilhado.

\section{MATERIAL E MÉTODOS}

O experimento foi conduzido em campo, na UNESP, em Jaboticabal, cujas coordenadas são $21^{\circ} 15^{\prime} 22$ ' Sul, 48 18'58" Oeste e altitude de 575 metros, de junho a novembro de 2001. Durante o período experimental, a temperatura média no interior do ambiente protegido foi de $25^{\circ} \mathrm{C}$ e as médias das mínimas e máximas foram de $15^{\circ} \mathrm{C}$ e $33^{\circ} \mathrm{C}$, respectivamente. A média da umidade relativa do ar mínima e máxima foram de 34 e $97 \%$, respectivamente.

A casa de vegetação onde instalouse a cultura era do tipo túnel alto, com lanternim, coberta com filme de polietileno de baixa densidade aditivado, de $150 \mathrm{~mm}$ de espessura, com pé direito de $3 \mathrm{~m}$, largura de $12,8 \mathrm{~m}$, comprimento de $51 \mathrm{~m}$ e sem fechamento lateral e frontal. O híbrido de melão (Cucumis melo var. reticulatus) utilizado foi o Bônus $\mathrm{n}^{\circ} 2$, sendo semeado dia 18/06/2001 em espuma fenólica (5,0 x $5,0 \times 3,8 \mathrm{~cm}$ ). O transplantio foi realizado aos 22 dias após a semeadura, para um sistema hidropônico tipo "nutrient film technique" (NFT), sendo o espaçamento adotado de 1,0 x 0,30 m.

O sistema hidropônico, constituiuse de quatro reservatórios de fibra de vidro, com capacidade para $1500 \mathrm{~L}$ cada, contendo separadamente as quatros soluções nutritivas em avaliação (80;140;
200 e $300 \mathrm{mg} \mathrm{L}^{-1}$ de N). Em cada reservatório foi instalada uma moto-bomba para bombeamento da solução nutritiva para os canais de cultivo feitos com tubos de polipropileno semicirculares com $15 \mathrm{~cm}$ de diâmetro, distando da superfície do solo em cerca de $50 \mathrm{~cm}$ em seu ponto mais alto e dispostos com declividade de $4 \%$, a fim de permitir o retorno da solução nutritiva aos reservatórios, por gravidade. Os canais apresentavam aberturas circulares de $5 \mathrm{~cm}$ de diâmetro na sua parte superior para a colocação das mudas.

$\mathrm{O}$ tempo de funcionamento e de repouso do sistema de bombeamento foi ajustado da seguinte forma: 10' ligado e 20 ' desligado no período de 7 às 10 horas e 10' ligado e 10' desligado no período subsequente até 18:30. À noite, foram feitas duas circulações da solução nutritiva com duração de 10 minutos, às 22 e 2 h. O volume de solução nutritiva bombeado por canal de cultivo foi mantido em 3,0 $\mathrm{L} \mathrm{min}^{-1}$, ficando dentro da faixa de 2,0 a 4,0 $\mathrm{L} \mathrm{min}^{-1}$, considerada adequada por Furlani et al. (1999).

A solução nutritiva utilizada baseouse na de Castellane e Araújo (1994) em relação aos macronutrientes e na de Furlani et al. (1999) para micronutrientes, e apresentou a seguinte concentração: 40; 165; 150; 24; 30; 0,3; 2,2; 0,6; 0,3; 0,05 e 0,05 $\mathrm{mg} \mathrm{L}^{-1}$ de P, K, Ca, Mg, $\mathrm{S}, \mathrm{B}, \mathrm{Fe}, \mathrm{Mn}, \mathrm{Zn}, \mathrm{Cu}$ e Mo, respectivamente. Para o preparo das soluções e balanceamento das quatro concentrações de $\mathrm{N}$ avaliadas foram utilizados os fertilizantes nitrato de potássio, nitrato de amônio, nitrato de cálcio, fosfato monoamônio, fosfato monopotássico, sulfato de potássio, cloreto de potássio, cloreto de cálcio, sulfato de magnésio, nitrato de magnésio, ácido bórico, sulfato de cobre, cloreto férrico + EDTA, sulfato de manganês, sulfato de zinco e molibdato de sódio.

A água utilizada na hidroponia tinha pH de 8,1 , condutividade elétrica de 0,1 $\mathrm{dS} \mathrm{m}^{-1}$, e concentrações de nitrogênio nas formas de nitrato, nitrito e amoniacal, respectivamente, 0,013 ; 0,006 e inferior a $0,001 \mathrm{mg} \mathrm{L}^{-1}$.

Durante o período experimental, o $\mathrm{pH}$ da solução nutritiva foi mantido na faixa de 5,5 a 6,5 e as condutividades elétricas (CE) medidas logo após o pre- paro das soluções foram 2,$81 ; 2,81 ; 3,07$ e $2,75 \mathrm{dS} \mathrm{m}^{-1}$, respectivamente, para as soluções com 80; 140; 200 e $300 \mathrm{mg} \mathrm{L}^{-1}$ de nitrogênio. Os valores de $\mathrm{CE}$ foram restabelecidos, aos iniciais, sempre que constatou-se redução de $10 \%$ aproximadamente, utilizando-se de solução nutritiva estoque com a mesma concentração de nutrientes da solução inicial correspondente. A solução nutritiva foi trocada, inicialmente, aos 30 dias após o transplantio (DAT) e posteriormente, a cada 15 dias para diminuir efeitos negativos na planta, resultantes de possíveis desbalanços nutricionais.

O delineamento experimental utilizado foi o de blocos casualizados, com esquema de parcelas subdivididas com quatro tratamentos principais (concentrações de nitrogênio) e quatro tratamentos secundários (número de frutos préestabelecidos por planta, 2; 3; 4 e livre), em seis repetições, sendo que cada unidade experimental foi constituída por oito plantas.

As plantas foram conduzidas em haste única e tutoradas por um fitilho plástico de modo a crescerem verticalmente. Foram deixados frutos nos brotos entre o $11^{\circ}$ e $17^{\circ}$ nó caulinar para a fixação de frutos em quantidade correspondente aos tratamentos com 2; 3 e 4 frutos por planta. No tratamento de fixação livre, foram deixados frutos a partir do $11^{\circ}$ nó. A desbrota foi realizada nos tratamentos com 2; 3 e 4 frutos por planta, após a fixação dos mesmos. Em todos os tratamentos, a haste lateral contendo o fruto e a haste principal tiveram seus meristemas apicais eliminados, respectivamente, duas folhas após o fruto e após o $23^{\circ}$ nó. Uma vez estabelecido o número de frutos do tratamento, procedeu-se a eliminação dos frutos excedentes. A polinização foi realizada por abelhas (Appis mellifera), colocadas próximas à casa de vegetação, no período de floração. Durante o ciclo da cultura foi realizado o controle de doenças causadas por Didymella bryoniae e Oidium spp. e também das pragas vaquinha (Diabrotica speciosa), mosca-branca (Bemisia tabaci), moscaminadora (Liriomiza sp.) e broca-dosfrutos (Diaphania nitidalis), com defensivos específicos recomendados para a cultura do meloeiro. 
Tabela 1. Teor de sólidos solúveis totais (TSS) e acidez do primeiro, segundo e terceiro fruto do meloeiro, híbrido Bônus ${ }^{\circ} 2$, cultivado em hidroponia, em função do número de frutos pré-estabelecidos por planta. Jaboticabal, UNESP-FCAV, 2002.

\begin{tabular}{|c|c|c|c|c|c|c|}
\hline \multirow{2}{*}{ Frutos/planta } & $1^{\circ}$ fruto & $2^{\circ}$ fruto & $3^{\circ}$ fruto & $1^{\circ}$ fruto & $2^{\circ}$ fruto & $3^{\circ}$ fruto \\
\hline & \multicolumn{3}{|c|}{ TSS ( ${ }^{\circ}$ Brix) } & \multicolumn{3}{|c|}{ Acidez $\left(\mathrm{g} 100 \mathrm{ml}^{-1}\right)$} \\
\hline 2 & $12,3 a^{1}$ & $12,7 \mathrm{a}$ & -- & $0,126 a$ & $0,132 \mathrm{a}$ & -- \\
\hline 3 & $11,8 \mathrm{~b}$ & $11,8 \mathrm{~b}$ & $12,5 \mathrm{a}$ & $0,118 a b$ & $0,117 \mathrm{~b}$ & $0,127 \mathrm{a}$ \\
\hline 4 & $11,7 \mathrm{~b}$ & $11,9 \mathrm{~b}$ & $12,3 \mathrm{a}$ & $0,119 a b$ & $0,117 \mathrm{~b}$ & $0,123 a$ \\
\hline Fixação livre & $11,6 \mathrm{~b}$ & $12,0 \mathrm{~b}$ & $12,3 \mathrm{a}$ & $0,115 b$ & $0,124 \mathrm{~b}$ & $0,125 \mathrm{a}$ \\
\hline C.V. (\%) & 5,4 & 6,2 & 5,0 & 9,5 & 8,3 & 8,9 \\
\hline
\end{tabular}

${ }^{1}$ Médias na coluna, seguidas de mesma letra, não diferem entre si, pelo teste de Tukey $5 \%$.

Após 114 dias do transplantio, iniciou-se a colheita que foi realizada durante 15 dias e foram avaliados: a) teor de sólidos solúveis totais, utilizando-se algumas gotas do suco do fruto, obtidas pela maceração do mesocarpo, sendo feita a leitura em refratômetro manual, e os valores expressos em graus Brix; b) acidez total titulável, obtida pela titulação de $\mathrm{NaOH}$ a $0,1 \mathrm{~N}$, sobre a diluição de $20 \mathrm{ml}$ de suco do fruto em 20 ml de água, usando como indicador, fenoftaleína, realizando-se posteriormente transformação dos valores obtidos segundo método proposto pelo Instituto Adolfo Lutz (1985), utilizando-se como fator de correção, o volume de $\mathrm{NaOH}$ titulado x 0,032 , o que proporciona valores em gramas de ácido cítrico $100 \mathrm{ml}^{-1}$ de solução; c) diâmetros longitudinal e transversal do fruto, obtidos com auxílio de paquímetro eletrônico; d) espessura da polpa, isto é, do mesocarpo do fruto, obtido com auxílio de paquímetro eletrônico; e) índice de formato do fruto, sendo obtido pela razão entre o diâmetro longitudinal e transversal do fruto.

Os dados foram submetidos à análise de variância, aplicando-se o teste de Tukey, a 5\% de probabilidade, e regressão polinomial para interpretação, respectivamente, dos efeitos dos fatores número de frutos pré-estabelecidos por planta e concentração de nitrogênio (BANZATO; KRONKA, 1995).

\section{RESULTADOS E DISCUSSÃO}

Na colheita, foram obtidos 2; 2,9; 3 e 3,4 frutos por planta, respectivamente, nas plantas conduzidas com 2; 3; 4 e fixação livre (sem desbaste de fruto). $\mathrm{O}$ menor número de frutos por planta na colheita é atribuído ao abortamento de frutos pelo meloeiro. Monteiro e Mexia (1988) constataram alto índice de abortamento de frutos, obtendo-se média de fixação de 2,6 frutos por planta onde estavam previstos fixação e condução de cinco frutos por planta. McGlasson e Pratt (1963) e Monteiro e Mexia (1988) atribuem ao intenso crescimento que ocorre no período entre o $5^{0}$ e o $10^{0}$ dia após a antese, período em que os frutos atingem $80 \%$ do seu diâmetro final, como a condição determinante para o abortamento dos frutos. Gusmão (2001) e Costa et al. (2004) também observaram considerável abortamento de frutos em melões rendilhados.

Não foi observado efeito significativo da interação entre a concentração de nitrogênio e o número de frutos por planta sobre o teor de sólidos solúveis do primeiro, segundo e terceiro fruto colhido. O fator concentração de nitrogênio, também não exerceu, isoladamente, efeito significativo sobre o teor de sólidos solúveis dos frutos.

Os resultados encontrados nesse experimento, assemelham-se aos obtidos por Wilcox (1973) e Faria et al. (2000) que não observaram diferenças significativas nos teores de sólidos solúveis dos frutos em função de doses crescentes de nitrogênio aplicado ao solo para o melão. Por outro lado, Rodrigues et al. (2001), trabalhando com melão do grupo inodorus em solo, verificaram diminuição do teor de sólidos solúveis à medida em que se aumentou a dose de nitrogênio.

A divergência nos resultados encontrados na literatura sugere que o efeito do nitrogênio sobre o teor de sólidos solúveis de frutos do meloeiro é muito mais indireto do que direto. Ao que parece, o efeito do nitrogênio sobre o teor de sólidos solúveis de frutos do meloeiro é dependente do efeito que o nitrogênio pode promover sobre outras características da planta, por exemplo área foliar.

$\mathrm{O}$ incremento obtido na área foliar do meloeiro, refletindo maior área foliar por fruto, promove incremento no teor de sólidos solúveis, conforme verificado por Monteiro e Mexia (1988), Welles e Buitelaar (1988). Essa pode ser a razão da não constatação de incremento no teor de sólidos solúveis do fruto de melão, mediante o aumento da concentração de $\mathrm{N}$ na solução nutritiva, uma vez que não foram observados incrementos na área foliar do meloeiro (média de 7.379,7 $\mathrm{cm}^{2}$ planta $^{-1}$ ) com crescentes concentrações de $\mathrm{N}$ na solução nutritiva (PURQUERIO et al., 2003).

Os valores médios de sólidos solúveis observados para o primeiro, segundo e terceiro fruto colhido foram, respectivamente, 11,$9 ; 12,1$ e $12,5^{\circ}$ Brix. Estes valores são inferiores aos observados por Cecílio Filho e May (2000), de $14,3^{\circ}$ Brix, para o "Bônus no 2 " em cultivo sem solo (substrato areia) e superiores aos encontrados por Pádua (2001), de $10,7^{\circ}$ Brix , para a mesma cultivar. Resultados semelhantes foram observados por Gualberto et al. (2001) e Gusmão (2001), em solo, os quais, respectivamente, obtiveram frutos com teor de sólidos solúveis entre 12,0 e $13,3^{\circ}$ Brix e 9 e $13^{\circ}$ Brix, em diferentes ambientes de cultivo, com o híbrido Bônus $n^{\circ} 2$.

Com base na proposta de McCreight et al. (1993), citado por Rizzo (1999), os frutos obtidos no presente trabalho encontram-se com teor de sólidos solúveis totais muito próximo ou dentro da faixa de 12 a $15^{\circ}$ Brix, o que confere o atributo 'excelente' aos mesmos.

$\mathrm{O}$ número de frutos por planta influenciou significativamente o teor de sólidos solúveis do primeiro e segundo fruto da planta. Maior teor de sólidos solúveis foi obtido em plantas com 2 frutos (Tabela 1). Resultados semelhantes foram obtidos por Monteiro e Mexia (1988), os quais observaram diminuição no valor de sólidos solúveis à medida que aumentou-se o número de frutos por planta. 
Não houve efeito significativo da interação entre concentração de nitrogênio e número de frutos por planta sobre a característica acidez total titulável do primeiro, segundo e terceiro fruto colhido. Porém, houve efeito isolado dos fatores avaliados, onde a crescente concentração de nitrogênio na solução nutritiva proporcionou aumento na acidez total titulável do primeiro, segundo e terceiro fruto colhido (Figura 1).

No primeiro e terceiro fruto da planta, a acidez dos mesmos aumentou linearmente com o incremento de nitrogênio na solução nutritiva, alcançando 0,128 e 0,132 g de ácido cítrico por 100 $\mathrm{ml}$ de suco, respectivamente. No segundo fruto colhido, a máxima acidez foi de $0,127 \mathrm{~g}$ de ácido cítrico por $100 \mathrm{ml}$ de suco, na concentração de $240 \mathrm{mg} \mathrm{L}^{-1}$ de nitrogênio na solução nutritiva. A partir de então, o aumento na concentração de nitrogênio da solução nutritiva determinou reduções na acidez do segundo fruto (Figura 1).

Maiores médias de acidez total titulável dos frutos, constatadas em soluções nutritivas mais ricas em nitrogênio podem ser atribuídas ao aumento na atividade metabólica da planta, de tal forma que possa ter ocorrido um efeito indireto do nitrogênio sobre a senescência da planta, atrasando-a, com reflexos proporcionais no grau de amadurecimento do fruto. Neste sentido, diferentes concentrações de nitrogênio na solução nutritiva podem ter determinado diferenças bioquímicas nos frutos, não perceptíveis visualmente na avaliação do ponto de colheita.

Não foi encontrada na literatura consultada, uma faixa adequada para acidez dos melões do grupo reticulatus. Porém, para melões em geral, de acordo com Mendlinger e Pastenak (1992) as quantidades de ácido cítrico variam de 0,05 a $0,35 \%$. As médias de acidez total titulável encontradas no presente experimento, situaram-se dentro do limite anteriormente apresentado e foram inferiores aos valores encontrados por Grangeiro et al. (1999), para híbridos de melão do grupo inodorus, que normalmente possuem sabor e aroma (flavor) considerados inferiores aos melões do grupo reticulatus, para a maioria das pessoas.

Wang et al. (1996) encontraram para a cultivar Makdimon (grupo reticulatus) aos 44 dias após a antese, frutos com

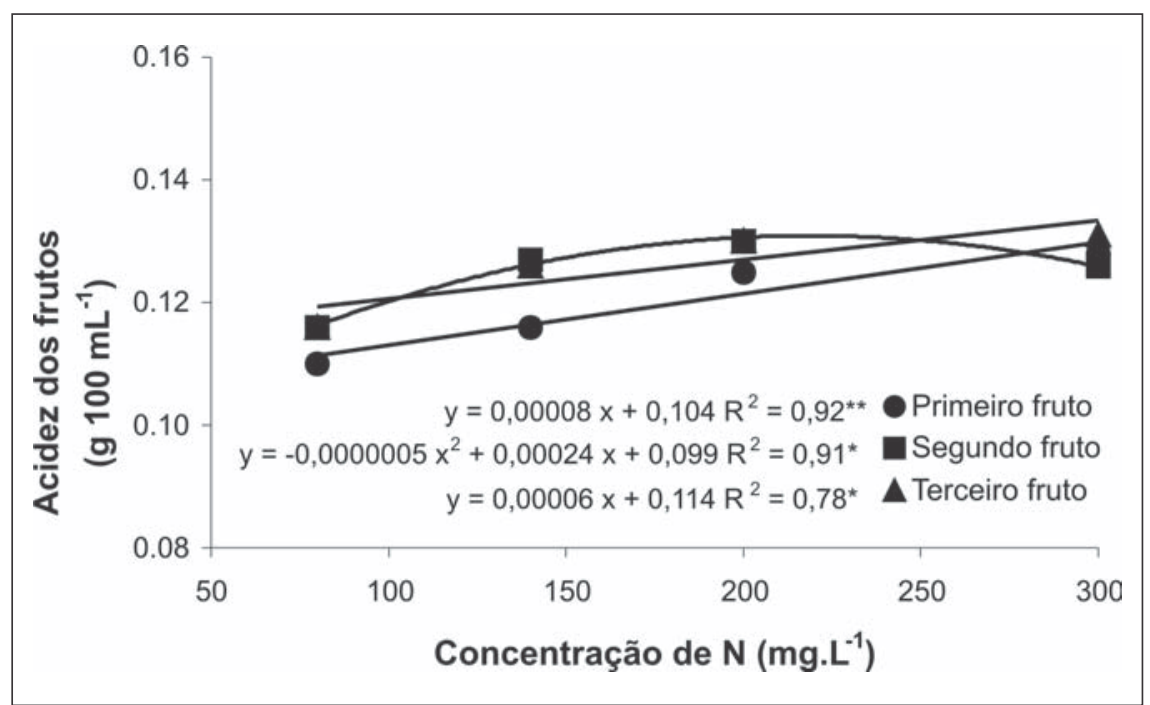

Figura 1. Acidez do primeiro, segundo e terceiro fruto colhido do meloeiro, híbrido Bônus $\mathrm{n}^{\circ} 2$, cultivado em hidroponia, em função da concentração de nitrogênio na solução nutritiva. Jaboticabal, UNESP-FCAV, 2002.

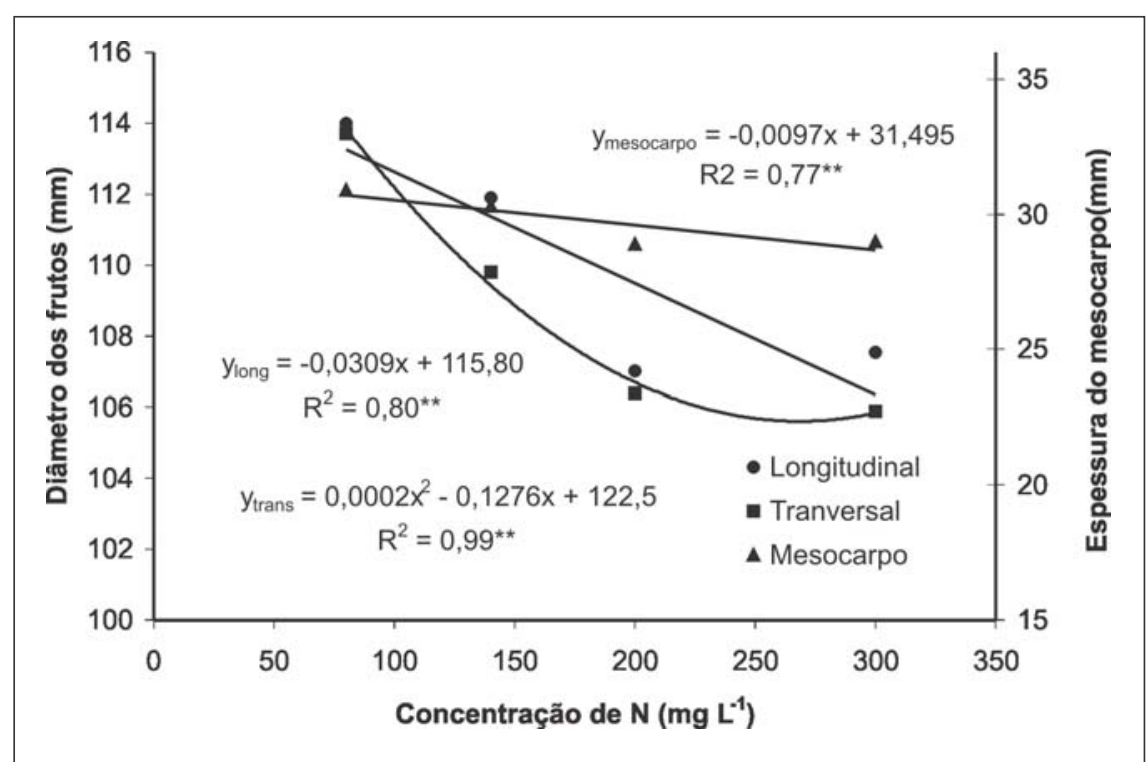

Figura 2. Espessura do mesocarpo, diâmetros longitudinal e transversal médios do fruto colhido do meloeiro, Bônus $n^{\circ}$ 2, cultivado em hidroponia, em função da concentração de nitrogênio na solução nutritiva. Jaboticabal, UNESP-FCAV, 2002.

0,2\% de ácido cítrico. Rizzo (1999), trabalhando em solo com adubação nitrogenada de $30 \mathrm{~kg} \mathrm{ha}^{-1}$, encontrou valores de acidez total titulável para o melão 'Bônus no 2' de 0,094 g de ácido cítrico $100 \mathrm{ml}^{-1}$, valores estes, pouco inferiores aos encontrados neste trabalho, enquanto que Villela Jr. (2001), trabalhando com $200 \mathrm{mg} \mathrm{L}^{-1}$ de nitrogênio na solução nutritiva, encontrou valor médio de $0,148 \mathrm{~g}$ de ácido cítrico $100 \mathrm{ml}^{-1}$.

$\mathrm{O}$ número de frutos pré-estabelecidos por planta também influenciou a acidez do primeiro e segundo fruto colhidos (Tabela 1). Maiores médias de acidez total titulável foram encontradas nas plantas com dois frutos, com tendência de redução na acidez dos frutos à medida em que elevou-se o número dos mesmos na planta. Para o terceiro fruto fixado, não houve efeito significativo do número de frutos pré-estabelecidos sobre a acidez total titulável.

As características relacionadas à dimensão e ao formato do fruto não foram influenciadas significativamente 
Tabela 2. Diâmetro longitudinal (DL), diâmetro transversal (DT), índice de formato de fruto (IFF) e espessura do mesocarpo (EM) de frutos colhidos do meloeiro, híbrido Bônus $n^{\circ}$ 2, cultivado em hidroponia, em função do número de frutos pré-estabelecidos por planta. Jaboticabal, UNESP-FCAV, 2002.

\begin{tabular}{lcccc}
\hline Frutos/planta & DL $(\mathbf{m m})$ & DT $(\mathbf{m m})$ & IFF & EM $(\mathbf{m m})$ \\
\hline 2 & $115 \mathrm{a}$ & $115 \mathrm{a}$ & $1,00 \mathrm{a}$ & $31 \mathrm{a}$ \\
3 & $109 \mathrm{~b}$ & $108 \mathrm{~b}$ & $1,00 \mathrm{a}$ & $29 \mathrm{~b}$ \\
4 & $109 \mathrm{~b}$ & $107 \mathrm{~b}$ & $1,01 \mathrm{a}$ & $29 \mathrm{~b}$ \\
Fixação livre & $107 \mathrm{~b}$ & $106 \mathrm{~b}$ & $1,00 \mathrm{a}$ & $28 \mathrm{~b}$ \\
\hline C.V. $(\%)$ & 3,6 & 3,4 & 2,5 & 5,0 \\
\hline
\end{tabular}

${ }^{1}$ Médias na coluna, seguidas de mesma letra, não diferem entre si, pelo teste de Tukey $5 \%$.

pela interação entre concentração de nitrogênio e número de frutos fixados por planta, sendo constatado apenas efeito significativo isolado dos fatores estudados. $\mathrm{O}$ aumento na concentração de nitrogênio na solução nutritiva, promoveu reduções nos diâmetros longitudinal e transversal dos frutos e na espessura média do mesocarpo (Figura 2). Os maiores valores observados de diâmetro longitudinal e transversal, respectivamente 133,3 e 113,6 mm, foram obtidos em solução contendo $80 \mathrm{mg} \mathrm{L}^{-1} \mathrm{de}$ nitrogênio. De maneira geral, os diâmetros encontrados nas diferentes concentrações de nitrogênio e fixações de fruto são superiores aos encontrados por Rizzo e Braz (2001) (102 e 104 mm), para o híbrido 'Bônus $\mathrm{n}^{\circ} 2$ ', cultivado no solo dentro de casa de vegetação e encontram-se muito próximos aos diâmetros longitudinal (119 e $111 \mathrm{~mm})$ e transversal (104 e $102 \mathrm{~mm}$ ) verificados, respectivamente, por Villela Jr. (2001) e Pádua (2001), ambos tendo cultivado "Bônus nº 2", em hidroponia, com 200 $\mathrm{mg} \mathrm{L}^{-1}$ de nitrogênio solução nutritiva e densidades de plantio de 20.000 e 27.770 plantas por hectare.

A concentração de $80 \mathrm{mg} \mathrm{L}^{-1}$ de nitrogênio, proporcionou frutos com a polpa mais espessa, $30,7 \mathrm{~mm}$ e a redução gradual até $300 \mathrm{mg} \mathrm{L}^{-1}$ de $\mathrm{N}$, onde os frutos apresentaram média de 28,5 mm. Segundo Costa e Pinto (1977), o fruto ideal deve ter mesocarpo espesso e cavidade interna pequena, atributos que conferem ao fruto melhor resistência ao transporte e maior durabilidade pós-colheita.

Os valores de espessura do mesocarpo encontrados no presente trabalho, com a menor concentração de nitrogênio $80 \mathrm{mg} \mathrm{L}^{-1}$, foram superiores aos valores médios encontrados por Pádua (2001), 23,7 mm, com o híbrido 'Bônus n' 2', cultivado em areia, usando $200 \mathrm{mg} \mathrm{L}^{-1}$ de nitrogênio na solução nutritiva e por Rizzo e Braz (2001), 28 $\mathrm{mm}$, cultivado no solo, em casa de vegetação. Gusmão (2001) encontrou espessura do mesocarpo variando de 29 a $33 \mathrm{~mm}$ para melões híbrido Bônus n² 2 , cultivados em casa de vegetação sob diferentes ambientes.

A redução dos diâmetros longitudinal, transversal e espessura do mesocarpo foram relacionados por Purquerio et al. (2003) como responsáveis pela redução no peso dos frutos e, conseqüentemente, da produtividade, que também decresceram com o aumento na concentração de nitrogênio na solução nutritiva.

O número de frutos por planta, também, influenciou significativamente os diâmetros longitudinal e transversal dos frutos colhidos, além da espessura do mesocarpo. Maiores diâmetros e maior espessura do mesocarpo foram observados em plantas com 2 frutos, diferindo significativamente dos obtidos em plantas com 3, 4 e frutificação livre (Tabela 2). Esse resultado está de acordo com o observado por Monteiro e Mexia (1988), que também verificaram redução no tamanho e peso médio de frutos à medida que aumentava o número de frutos colhidos por planta, atribuindo-se à menor relação fonte (área foliar) e dreno (frutos).

O índice de formato do fruto em melão é um atributo de qualidade, sendo obtido pela razão entre o diâmetro longitudinal e o diâmetro transversal do fruto, sendo importante para a definição da classificação e padronização dos frutos e poderá determinar a melhor aceitação e valorização do produto para determinados tipos de mercado.

As reduções observadas nos diâmetros longitudinal e transversal dos frutos, com o aumento da concentração de nitrogênio e do número de frutos fixados, foram proporcionais, mantendo-se o índice de formato de fruto próximo ou igual a 1 (Tabela 2), e mostrando que o formato esférico do fruto não é alterado com a variação das condições de cultivo avaliadas.

O conhecimento do índice de formato de fruto também é importante para a definição da embalagem e do arranjo dos frutos no interior dela, sendo preferível índices próximos de um, como observados neste estudo, pois acima e abaixo deste valor os frutos ficam, respectivamente, alongados e achatados, comprometendo a sua acomodação nas embalagens.

Tendo em vista os resultados obtidos no presente trabalho, pode-se concluir que o incremento de 80 para 300 $\mathrm{mg} \mathrm{L}^{-1}$ de nitrogênio na solução nutritiva proporcionou um pequeno aumento na acidez total titulável dos frutos, sem afetar significativamente o teor de sólidos solúveis totais, enquanto que o aumento no número de frutos por planta determinou redução no teor de sólidos solúveis totais. As características relacionadas à dimensão e ao formato do fruto (diâmetro longitudinal, transversal e espessura do mesocarpo) diminuíram com o aumento da concentração de 80 para $300 \mathrm{mg} \mathrm{L}^{-1}$ de nitrogênio na solução nutritiva e com o aumento do número de frutos por planta; $O$ índice de formato de fruto manteve-se igual ou muito próximo a 1 , demonstrando ser uma característica não influenciável pela concentração de nitrogênio na solução nutritiva e pelo número de frutos na planta.

\section{AGRADECIMENTOS}

A FAPESP, pelo auxílio pesquisa concedido (processo $n^{\circ}$ 2000/01798-6) e ao CNPq pela bolsa de produtividade em pesquisa ao segundo autor.

\section{LITERATURA CITADA}

BANZATO, D.A.; KRONKA, S.N. Experimentação agrícola. 3. ed. Jaboticabal: FUNEP, 1995. 247 p. 
BHELLE, H.S.; WILCOX, G.E. Yield and composition of muskmelon as influenced by preplant and trickle applied nitrogen. HortScience, v.21, n.1, p.86-88, 1986.

CASTELLANE, P.D.; ARAÚJO, J.A.C. Cultivo sem solo: hidroponia. Jaboticabal: FUNEP, 1994 $43 \mathrm{p}$.

CECILIO FILHO, A.B.; MAY, A. Produtividade de duas cultivares de meloeiro e qualidade de seus frutos, em dois substratos. Horticultura Brasileira, Brasília, v.18, suplemento. p.537-538, 2000. COSTA, C.C.; CECÍlIO FILHO, A.B. CAVARIANNI, R.L.; BARBOSA, J.C. Produção do melão rendilhado em função da concentração de potássio na solução nutritiva e do número de frutos por planta. Horticultura Brasileira, Brasília, 2004 (no prelo).

COSTA, C.P.; PINTO, C.A.B.P. Melhoramento de hortaliças. Piracicaba: ESALQ, Depto. de Genética, 1977. 319 p.

EPSTEIN, E. Nutrição mineral de plantas: princípios e perspectivas. São Paulo:/Rio de Janeiro: USP e Livros Técnicos e Científicos, 1975. 341 p.

FARIA, C.M.B.; PEREIRA, J.R.; POSSÍDEO, E.L. Adubação orgânica e mineral na cultura do melão em um Vertissolo do Submédio São Francisco. Pesquisa Agropecuária Brasileira, Brasília, v.29, n.2, p.183-190, 1994.

FARIA, C.M.B.; COSTA, N.D.; PINTO, J.M. BRITO, L.T.L.; SOARES, J.M. Níveis de nitrogênio por fertirrigação e densidade de plantio na cultura do melão em um vetissolo. Pesquisa Agropecuária Brasileira, Brasília, v.35, n.3, p.491495, 2000.

FONSECA, J.R. Efeitos de doses de nitrogênio e fósforo sobre a qualidade do melão. Horticultura Brasileira, Brasília, v.19, 2001. Suplemento 1, CR-ROM.

FURLANI, P.R.; SILVEIRA, L.C.P. BOLONHEZI, D.; FAQUIN, V. Cultivo hidropônico de plantas. Campinas: IAC, 1999. 52 p. (Boletim Técnico 180).

GRANGEIRO, L.C.; PEDROSA, J.F.; NETO, F.B.; NEGREIROS, M.Z. Qualidade de híbridos de melão amarelo em diferentes densidades de plantio. Horticultura Brasileira, Brasília, v.17, n.2 p.110-113, 1999.
GUALBERTO, R.; RESENDE, F.V.; LOSASSO, P.H.L. Produtividade e qualidade do melão rendilhado em ambiente protegido, em função do espaçamento e sistema de condução. Horticultura Brasileira, Brasília, v.19, n.3, p.373-376, 2001.

GUSMÃO, S.A.L. Interação genótipo x ambiente em híbridos de melão rendilhado (Cucumis melo var. reticulatus Naud.). 2001. 143 p. (Tese Doutorado) - FCAV-UNESP, Jaboticabal

INSTITUTO ADOLFO LUTZ. Normas analíticas: métodos químicos e físicos para análises de alimentos. 2ed. São Paulo, 1985, v.1, 371 f.

McGLASSON, W.B.; PRATT. H.K. Fruit-set patterns and fruit growth en Cantaloup (Cumumis melo L. var. reticulatus ) Proceedings of American Society for Horticultural Science, v.83 p.495-505. 1963.

MALAVOLTA, E.; VITTI, G.C.; OLIVEIRA, S.A. Avaliação do estado nutricional das plantas: princípios e aplicações. 2. ed. Piracicaba: Potafos, 1997. 319 p.

MARSCHNER, H. Mineral nutrition of higher plants. San Diego: Academic Press, 1995. 889 p. MENGEL, K.; KIRKBY, E.A. Principles of plant nutrition. Bern, International Potash Institute, 1987. 687 p.

MENDLINGER, S.; PASTENAK, D. Effect of time, salination of flowering, yield and quality factors in melon, Cucumis melo L. Journal of the American Society for Horticultural Science, v.67, n.4, p.529-534, 1992.

MONTEIRO, A.A.; MEXIA, J.J. influência da poda e do número de frutos por planta na qualidade dos frutos e produtividade do melão. Horticultura Brasileira, v.6, n.1, p.9-12, 1988.

NERSON, H; COHEN, R.; EDELSTEIN, M.; BURGER, Y. Paclobutrazol - a plant growth retardant for increasing yield and fruit quality in muskmelon. Journal of the American Society for Horticultural Science, v.114, n.5, p.762-66, 1989. PÁDUA, J.G. Cultivo protegido de melão rendilhado, em duas épocas de plantio. Jaboticabal 2001. 108 f. (Tese doutorado) - FCAV-UNESP, Jaboticabal.

PARDOSSI, A.; LANDI, S.; MALORGIO, F.; CECCATELLI, M.; TOGNONI, F. Studies on melon grown with NFT. Acta Horticulturae, v.361, p.186-193, 1994.
PRABHAKAR, B.S.; SRINIVAS, K.; SHUKLA, V. Yield and quality of muskmelon (cv. Hara madhu) in relation to spacing and fertlization. Progressive Horticulture, v.17, n.1, p.51-55, 1985. PURQUERIO, L.F.V.; CECÍLIO FILHO, A.B.; BARBOSA, J.C. Efeito da concentração de nitrogênio na solução nutritiva e do número de frutos por planta sobre a produção do meloeiro. Horticultura Brasileira, Brasília, v.21, n.2, p.186191, 2003.

RESH, H.M. Cultivos hidroponicos: nuevas técnicas de producción. Madrid: Mundi-Prensa, 1997. 509 p.

RIZZO, A.A.N. Avaliação de caracteres agronômicos e qualitativos de 5 cultivares de melão rendilhado (Cucumis melo var. reticulatus Naud.) e da heteroze em seus híbridos F1. 1999. $61 \mathrm{f}$ Dissertação (Mestrado em Agronomia-Área de Concentração em Produção Vegetal) - Faculdade de Ciências Agrárias e Veterinárias, Universidade Estadual Paulista, Jaboticabal.

RIZZO, A.A.N.; BRAZ, L.T. Características de cultivares de melão rendilhado cultivadas em casa de vegetação. Horticultura Brasileira, Brasília, v.19, n.3, p.370-373, 2001

RODRIGUES, V.L.P.; SILVA, P.S.L.; GUIMARÃES, A.A.; SANTOS JÚNIOR, J.J. TORRELLARDONA, S.D. Frigoconservation de la fruta. Barcelona: Aedes, 1983. 283 p.

VILLELA JUNIOR, L.V.E. Cultivo hidropônico do meloeiro com a utilização de efluente de biodigestor. 2001. 116 f. Dissertação (Mestrado em Agronomia) - Faculdade de Ciências Agrárias e Veterinárias, Universidade Estadual Paulista, Jaboticabal

WANG, Y.; WYLLIE, S.G.; LEACH, D.N. Chemical changes during the development and ripening of the fruit of Cucumis melo (cv. Makdimon). Journal Agricultural Food Chem, v.44, p.210-216, 1996.

WELLES, G.W.H.; BUITELAAR, K. Factors affecting soluble solids content of muskmelon (Cucumis melo L.). Nethrlands Journal of Agricultural Science, v.36, p.239-246, 1988.

WILCOX, G.E. Muskmelon response to rates and sources of nitrogen. Agronomy Journal, v.65, p. 694-697, 1973. 